\title{
Geographic variation in seaweed induced responses to herbivory
}

\author{
Jeremy D. Long ${ }^{*}$, Geoffrey C. Trussell \\ Marine Science Center, Northeastern University, 430 Nahant Road, Nahant, Massachusetts 01908, USA
}

\begin{abstract}
Recent work on European (Swedish and English) populations of Ascophyllum nodosum has detected inducible defenses in response to snail grazing that include a decrease in algal palatability and an increase in phlorotannin concentration, a class of potential chemical defenses. However, tests of induced responses in other $A$. nodosum populations are lacking and we thus have a limited understanding of how widespread such responses are in fucoid algae. We exposed a North American (Massachusetts) A. nodosum population to Littorina obtusata, the same snail species used in previous studies, and tested for the presence of inducible responses during 2 experiments. In contrast to European populations, the North American population of A. nodosum did not develop any such responses. Exposure to either direct grazing or just waterborne cues associated with grazing for $26 \mathrm{~d}$ failed to suppress the palatability of artificial foods made from seaweed tissues exposed to these treatments. In addition, exposure to grazer cues did not increase seaweed phlorotannin levels compared to controls. The lack of induced responses in the North American population cannot be attributed to tissue type or potential seasonal variation in inducibility because each of our 2 independent experiments tested for responses in 2 tissue types (apical tips and basal shoots) in both the winter and spring. Furthermore, consistent with European work, the North American population lacked obvious grazing damage at the time of collection, suggesting that the differences we observed were unrelated to recent history with grazers. Thus, our work and that of others indicates that $A$. nodosum displays considerable inter-population variability in its response to a single herbivore species.
\end{abstract}

KEY WORDS: Consumer-prey interaction · Inter-population variation · Phenotypic plasticity Resale or republication not permitted without written consent of the publisher

\section{INTRODUCTION}

Several species of plants, vertebrates, invertebrates, phytoplankton, and seaweeds respond to consumers by altering their morphology, chemistry, or behavior (Bronmark \& Miner 1992, Karban \& Baldwin 1997, Tollrian \& Harvell 1999, Toth \& Pavia 2000, Trussell et al. 2003, 2004). These responses can provide a defensive function by reducing the vulnerability of the responding species to consumption. Plasticity theory predicts that inducible defenses should evolve in populations where the impact of consumers is relatively high but remains sufficiently variable in space and time to favor the maintenance of inducible over constitutive defenses (Van Tienderen 1991, Tollrian \& Harvell 1999, Trussell \& Nicklin 2002). Geographic variation in inducible defenses may arise in prey populations having broad geographic ranges and limited dispersal because of adaptive responses to local environmental conditions such as consumer abundance. Although we have a good sense of the diverse taxa exhibiting adaptive inducible defenses, we have a surprisingly poor knowledge of the geographic variation in inducible defenses within a species (but see Trussell 2000, Trussell \& Smith 2000). Attention to such variability will shed important light on the evolution of inducible defenses and their ecological importance.

Swedish populations of the seaweed Ascophyllum nodosum respond to direct grazing and waterborne cues from the herbivorous snail Littorina obtusata with inducible chemical defenses. These responses are likely to have a major impact on the population biology 
and life history of the inducing consumer because they suppress both herbivore feeding (Pavia \& Toth 2000, Toth \& Pavia 2000) and egg hatching rates (Toth et al. 2005). The underlying mechanism of induction observed in these studies may involve chemical defenses of $A$. nodosum because (1) artificial foods made from induced seaweeds lacking morphological defenses also suppressed snail grazing (Toth \& Pavia 2000) and (2) snail grazing increased the concentration of phlorotannins (Pavia \& Toth 2000, Toth \& Pavia 2000, Toth et al. 2005), which are widely thought to serve as defensive compounds in brown algae (but see Kubanek et al. 2004 for an exception). Recent evidence suggests that a southern England $A$. nodosum population also exhibits inducible defenses that suppress herbivore feeding and alter habitat preference (Borell et al. 2004). Given its broad geographic range (the eastern coast of North America to Europe) and short dispersal distance (Chapman 1995, Dudgeon et al. 2001), one would expect a high degree of local adaptation in A. nodosum, but more work is needed to determine how widespread inducible defenses are in this and other algal species.

This study explored whether inducible defenses exist in a North American (Massachusetts) population of Ascophyllum nodosum. By utilizing the methods similar to those in previous studies of European A. nodosum populations, we also sought to facilitate a robust comparison of geographic variation in inducible defenses. Hence, we exposed seaweeds to direct grazing or waterborne cues from Littorina obtusata and then tested for changes in herbivore palatability and phlorotannin concentration.

\section{MATERIALS AND METHODS}

Our experiments were divided into 2 sequential phases: the induction phase and the bioassay phase. During the induction phase, we grew knotted wrack Ascophyllum nodosum (class Phaeophyceae) in the presence or absence of herbivores for $26 \mathrm{~d}$ in outdoor mesocosms. Similar experimental durations induced defenses in European populations of A. nodosum (14 d, Borell et al. 2004, Toth et al. 2005; 21 d, Toth \& Pavia 2000; 14 to 28 d, Pavia \& Toth 2000). Seaweeds were collected at the end of the induction phase, incorporated into artificial foods, and offered to another set of herbivores in 2-choice experiments during the bioassay phase. Artificial foods made from A. nodosum displaying herbivore-induced resistance should be less palatable than foods made from seaweeds that grew in the absence of grazer cues (Pavia \& Toth 2000, Toth \& Pavia 2000). We also measured differences in phlorotannin levels of these seaweeds at the end of the induc- tion phase. We conducted this experiment in 2 different seasons, winter and spring, to test for seasonal variability in inducible defenses (Molis et al. 2006). The winter experiment started on November 20, 2004 and the spring experiment on April 22, 2005.

Induction phase. Co-occurring Littorina obtusata and whole Ascophyllum nodosum without severe grazing damage were collected from the intertidal zone at Pumphouse Beach adjacent to Northeastern University's Marine Science Center, Nahant, Massachusetts $\left(42^{\circ} 25.028^{\prime} \mathrm{N}, 70^{\circ} 54.456^{\prime} \mathrm{W}\right)$. Any resident herbivores were removed from all seaweeds prior to the start of the induction phase. We exposed seaweeds to either direct contact with grazers ('upstream' compartments), just the waterborne cues from these grazers ('downstream' compartments), or no grazer cues in our controls.

Individual seaweeds were added to each of 2 compartments ( $\sim 1$ volume) of plastic utility boxes separated by a perforated barrier (diameter of holes = $3 \mathrm{~mm}$ ). We added 10 intermediate-sized Littorina obtusata (shell length $\sim 8 \mathrm{~mm}$ ) to the upstream compartment of grazer treatments $(\mathrm{N}=9)$. This density is representative of those naturally occurring on individual Ascophyllum nodosum in the field (J. D. Long pers. obs.). No grazers were added to either compartment of grazer-free controls $(\mathrm{N}=9)$. For each replicate, flowing seawater entered the upstream compartments at $\sim 11$ $\mathrm{min}^{-1}$ and passed through the perforated barrier before entering the downstream compartments. This design allowed downstream seaweeds in grazer treatments to be exposed to potential chemical cues that might be released from grazed conspecifics without actually being attacked by herbivores. Logistical constraints prevented independent manipulation of upstream and downstream treatments.

Each utility box was contained within larger plastic basins to prevent cross-contamination of potential waterborne cues between treatments. Treatment and control replicates were paired and placed next to each other in outdoor tanks. Pairing replicates minimized the effects of variable light exposure and flow rates within tanks. Mesh bags (openings less than $500 \mu \mathrm{m}$ ) filtered out other macroalgae and herbivores (e.g. amphipods) from the seawater supply before entering the upstream compartment. To reduce the buildup of detritus, seaweeds were rinsed with seawater every 4 to $7 \mathrm{~d}$.

Bioassay phase. After the induction phase, we took digital photographs of seaweeds that were later processed and analyzed with ImageJ (Version 1.33u) to determine total grazing scar area. From each seaweed, we then collected 2 samples of apical tips and basal shoots. Apical tips consisted of apical areas of active growth and basal shoots consisted of mid-plant por- 
tions of old growth. Examination of multiple tissues allowed us to test whether inducible defenses in Ascophyllum nodosum are tissue-specific as they are for other brown algae (Sotka et al. 2002, Taylor et al. 2002). One sample was immediately extracted for phlorotannin analysis and the other was used in feeding bioassays. No tissues with reproductive vesicles or air bladders were selected. In the winter experiment, feeding assay samples were frozen at $-10^{\circ} \mathrm{C}$, freezedried, and then ground individually using a mortar and pestle. In the spring experiment, we altered the protocol slightly to minimize chemical changes that may occur during slow freezing. Instead of using a freezer, samples were frozen with liquid nitrogen, ground, and then freeze-dried.

We used Littorina obtusata consumption to measure (1) the relative palatability of apical tips and basal shoots of directly grazed plants compared to equivalent control tissues and (2) the relative palatability of tissues from downstream plants compared to equivalent control tissues. To facilitate a comparison of our results with those of Toth \& Pavia (2000), we created artificial agar-based foods from our treatment and control seaweeds using the protocol adopted from Lindquist \& Hay (1996). Artificial foods consisted of $5.6 \%$ ground, freeze-dried algae (w:v) and $2.0 \%$ agar $(\mathrm{w}: \mathrm{v})$. Solutions were poured into circular molds (1.27 $\mathrm{cm}$ diameter, $0.24 \mathrm{~cm}$ deep, $~ 0.3 \mathrm{ml}$ volume each) that sat on window screen. Molding foods onto window screen enabled us to minimize handling disturbance to artificial foods. Once foods had cooled, we submerged them in seawater to prevent desiccation. The starting mass of foods, including window screen, was $413 \pm$ $2 \mathrm{mg}$ and $442 \pm 2 \mathrm{mg}$ in the winter and spring, respectively. Window screen represented approximately $50 \mathrm{mg}$ of these masses.

Littorina obtusata were collected from the field and kept in the laboratory with Ascophyllum nodosum as food for less than $48 \mathrm{~h}$. Six large $(>1 \mathrm{~cm})$ L. obtusata were offered a choice between artificial foods made from control or treatment seaweeds. Each group of grazers was matched with 1 of the 9 replicates from the induction phase to achieve true replication $(\mathrm{N}=9)$. Assays were stopped after $4 \mathrm{~d}$ or when half of one of the foods was consumed, after which we measured the final wet masses of artificial foods. Grazing rates were corrected for autogenic changes in grazer-free controls using the formula $T_{\mathrm{i}}\left(C_{\mathrm{f}} / C_{\mathrm{i}}\right)-T_{\mathrm{f}}$, where $T_{\mathrm{i}}$ and $T_{\mathrm{f}}$ represent the initial and final masses of artificial foods subjected to grazing, respectively, and $C_{\mathrm{i}}$ and $C_{\mathrm{f}}$ represent the initial and final masses of control foods, respectively (equation from Sotka et al. 2002).

For each seaweed, we measured the total phlorotannin concentration of the 2 tissue types (apical tips, basal shoots) following the Folin-Ciocalteu method
(Van Alstyne 1995, Toth \& Pavia 2000). Tissue samples were homogenized and extracted in $80 \%$ methanol at $4^{\circ} \mathrm{C}$ for $24 \mathrm{~h}$. Then, $50 \mu \mathrm{l}$ of extract were diluted with $1 \mathrm{ml}$ deionized water and $1 \mathrm{ml} 40 \%$ Folin-Ciocalteu reagent. After $5 \mathrm{~min}, 1 \mathrm{ml}$ of a saturated sodium carbonate solution was added. Samples were vortexed, and then heated in a $50^{\circ} \mathrm{C}$ water bath for $30 \mathrm{~min}$. Absorbance was read at $760 \mathrm{~nm}$ and compared to a standard curve generated with phloroglucinol (Sigma) samples. Phlorotannin concentration was corrected by a seaweed dry:wet mass ratio, and these data are reported as \% dry mass.

We analyzed grazing choice experiments using 2-tailed, paired $t$-tests because choices were paired in the bioassay phase. Paired $t$-tests are frequently used to analyze 2-choice feeding experiments similar to those reported here (Cronin \& Hay 1996, Stachowicz \& Hay 1999, Pavia \& Toth 2000). We also analyzed phlorotannin concentrations with 2-tailed, paired $t$-tests because treatment and control replicates were paired in the induction phase to minimize the effects of variable abiotic factors (e.g. light intensity and flow).

For logistical reasons, we were unable to use a completely orthogonal design to test for inducible defenses in Ascophyllum nodosum for multiple grazer cues (direct contact, waterborne cues) on multiple seaweed tissues (apical tips, basal shoots). We conducted multiple $t$-tests on our data although neither grazer cues nor tissues were independent from each other. This statistical procedure can lead to an increased probability of a Type I error (i.e. incorrectly rejecting the null hypothesis of no difference between populations). However, we are confident in our conclusion of no statistical difference between grazing rates on treatment and control foods because applying a correction for multiple $t$-tests, such as a Bonferroni correction, would have decreased our probability of rejecting the null hypothesis (i.e. after the correction, we would be more likely to arrive at the same conclusion). Furthermore, multiple paired $t$-tests have been used to assess inducible defenses of non-independent grazer cues and tissues in previous studies (Bolser \& Hay 1998, Sotka et al. 2002, Taylor et al. 2002).

We closely mimicked the 2 previous studies to examine the effects of inducible defenses on snail feeding (Pavia \& Toth 2000, Toth \& Pavia 2000). Seaweeds for all 3 studies lacked severe grazing damage at the time of collection. The induction phases exposed Ascophyllum nodosum to Littorina obtusata grazing for 14 to $28 \mathrm{~d}$ in shaded, outdoor mesocosms. The bioassay phases lasted 3 to $6 \mathrm{~d}$ and the Folin-Ciocalteu method measured phlorotannin levels in all 3 studies. Therefore, differences between these studies are unlikely to be due to differences in experimental design. 


\section{RESULTS}

Littorina obtusata failed to induce responses in the North American (Massachusetts) population of Ascophyllum nodosum. Previous grazing by L. obtusata neither reduced algal palatability (Fig. 1) nor increased algal phlorotannin concentration (Fig. 2). This lack of induction was evident in 2 seasons, winter and spring.

During the winter, feeding rates on foods made from seaweeds exposed to either grazers or just waterborne grazer cues were greater than those on control foods, but these differences were not significantly different (Fig. 1A,C). Similarly, feeding rates on foods made from seaweeds exposed to either grazers or just waterborne grazer cues were never significantly suppressed compared to equivalent control tissues during the spring (Fig. 1B,D). Compared to feeding on control foods, feeding rates were significantly greater on foods made from basal shoots receiving waterborne cues in the spring $(p=0.050$, Fig. 1D) and marginally greater in the winter for foods made from directly grazed basal shoots $(p=0.057$, Fig. 1 A) and apical tips receiving waterborne grazer cues ( $p=0.063$, Fig. $1 \mathrm{C})$.

Phlorotannin concentrations were not enhanced after exposure to either direct grazing or waterborne grazer cues (Fig. 2). Surprisingly, spring phlorotannin levels were significantly reduced in apical tips exposed to direct grazing ( $p=0.022$, Fig. $2 \mathrm{~B})$ and basal shoots exposed to waterborne cues ( $p=0.038$, Fig. 2D).

Grazing scars covered at least 15 times more area in seaweeds exposed to direct grazing than control seaweeds, and control seaweeds showed little evidence of

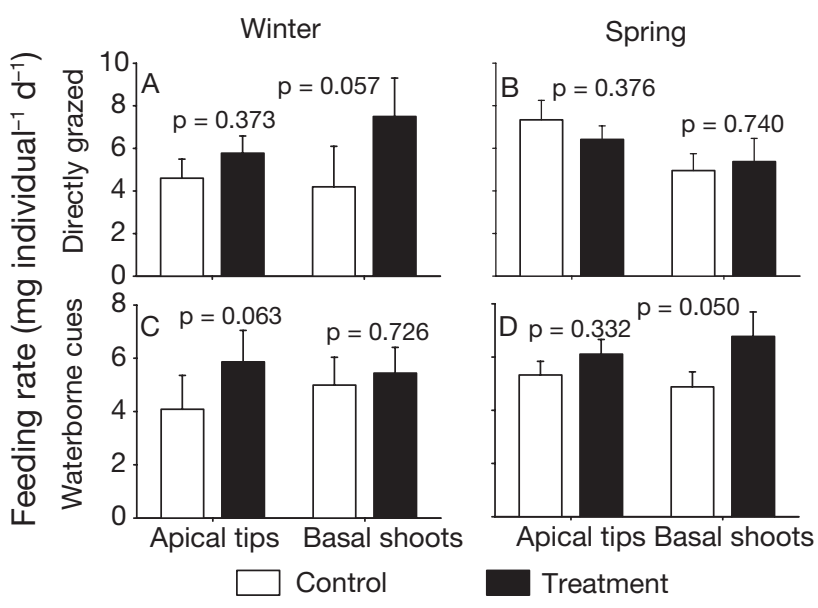

Fig. 1. Littorina obtusata. Mean +1 SE feeding rates of snails offered a choice between artificial foods made from Massachusetts Ascophyllum nodosum previously exposed to grazer cues or grazer-free controls. (A,B) Previously grazed by L. obtusata; $(\mathrm{C}, \mathrm{D})$ previously exposed to waterborne grazer cues. Experiment was conducted in 2 seasons, winter and spring. Feeding rates on treatment relative to controls were compared using paired $t$-tests

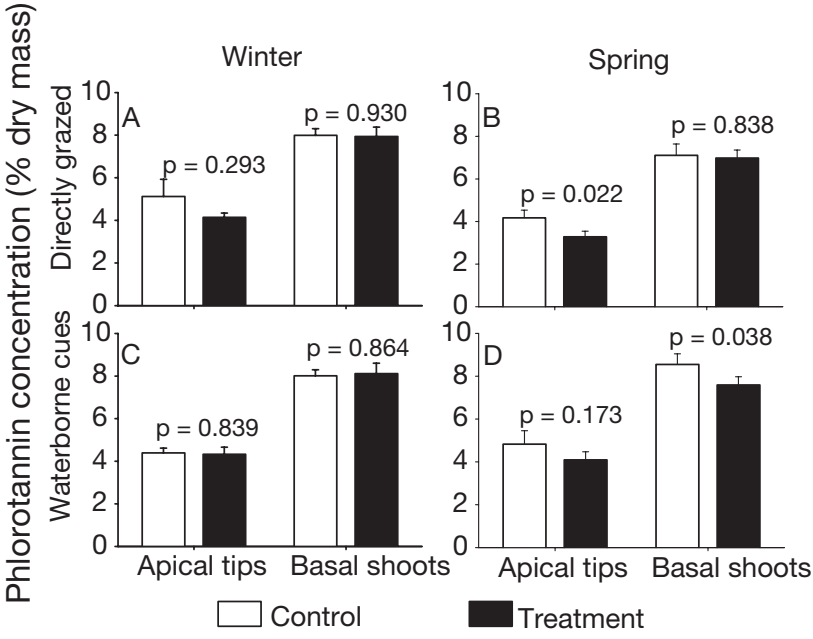

Fig. 2. Ascophyllum nodosum. Mean + 1 SE phlorotannin concentration of Massachusetts A. nodosum previously exposed to grazer cues or grazer-free controls. $(A, B)$ Previously grazed by L. obtusata; $(\mathrm{C}, \mathrm{D})$ previously exposed to waterborne grazer cues. Experiment was conducted in 2 seasons, winter and spring. Treatment and control concentrations were compared using paired $t$-tests

grazing. In the winter, grazing scars covered $4.45 \pm$ $0.98 \mathrm{~cm}^{2}$ and $0.30 \pm 0.09 \mathrm{~cm}^{2}$ of directly grazed and control seaweeds, respectively. In the spring, grazing scars covered $3.37 \pm 1.08 \mathrm{~cm}^{2}$ and $0.10 \pm 0.07 \mathrm{~cm}^{2}$ of directly grazed and control seaweeds, respectively. Hence, snail grazing rates did not appear to differ across seasons.

\section{DISCUSSION}

This study and those of others suggest that Ascophyllum nodosum displays remarkable inter-population variation in inducible defenses across a broad geographic scale. A. nodosum from European populations consistently respond to either direct grazing by Littorina obtusata or waterborne grazer cues by increasing phlorotannin concentration and becoming less palatable to snails (Pavia \& Toth 2000, Toth \& Pavia 2000, Toth et al. 2005). Despite laboratory exposure to the same herbivore species for similar durations, individuals from our North American A. nodosum population failed to induce resistance; exposure to snails did not increase seaweed phlorotannin concentration nor did it suppress palatability. The lack of induction in North American individuals was consistent for two tissue types, across two different seasons. Thus, it appears that $A$. nodosum has evolved considerably different strategies to adapt to the risk of grazing.

Geographic variation in inducible defenses should occur when (1) the responding prey species has traits 
(e.g. poor dispersal relative to range size) that promote high local adaptation and (2) conditions (e.g. variable risk) favoring inducible defenses vary across the species' range. Local adaptation is likely in Ascophyllum nodosum because it typically disperses only a few meters but ranges across several thousand kilometers (Chapman 1995, Dudgeon et al. 2001). Limited dispersal also occurs in the marine snail Littorina obtusata because it lacks a planktonic larval stage and produces crawl-away larvae (Reid et al. 1996) which may account for its inter-population variation in inducible defenses (Trussell 2000, Trussell \& Smith 2000). Such poor dispersal and thus limited gene flow in both species may promote pronounced variation in inducible defenses among widely separated populations.

Moreover, plasticity theory predicts that constitutive defenses should evolve under more intense consumer pressure, and aquatic communities provide some of the best support for this prediction. Tropical oceans (compared to temperate oceans) and Australasian oceans (compared to NE Pacific oceans) where herbivory is more intense, contain better defended seaweeds (Steinberg 1992, Bolser \& Hay 1996). However, the limitations of such cross-species contrasts are well known (Van Alstyne 2001, Amsler \& Fairhead 2006). Fortunately, intraspecific comparisons are consistent with theory - populations of plants and aquatic invertebrates from habitats with greater recent and historical levels of consumer pressure have stronger constitutive defenses (Trussell \& Smith 2000, Pennings et al. 2005).

Plasticity theory also predicts that habitats with variable or unpredictable levels of consumer pressure favor the evolution of inducible defenses. Unfortunately, explicit tests of this prediction are rare, perhaps owing to the logistical constraints of inducing multiple prey populations. Most tests of inducible defenses focus on single prey populations or populations separated by small geographic distances (Harvell 1998, Stout et al. 1998, Rohde et al. 2004, but see Parejko \& Dodson 1991, Trussell 2000, and Trussell \& Smith 2000 for exceptions). In 2 studies, the induced increases in snail shell thickness in response to waterborne risk cues from the predatory green crab Carcinus maenas were much greater for populations from northern latitudes compared to those from southern latitudes in the Gulf of Maine (Trussell 2000, Trussell \& Smith 2000). Although the reasons for this geographic variation in inducible defenses remain unclear, this variation probably evolved because snail populations have had, and continue to have, more consistent interactions with the green crab in the southern Gulf of Maine. These studies suggest that an appreciation for geographic variation will lead to a better understanding of the ecological significance of induced defenses. For example, future studies should compare the behavioral and pop- ulation traits of herbivores encountered by Ascophyllum nodosum on broad spatial scales.

In addition to biogeographic differences in the inducible defenses of seaweeds, the pattern described here may be generated by differences in constitutive levels of seaweed defenses and local herbivore tolerance for such defenses. Marine herbivores co-occuring with chemically defended seaweeds typically have a greater tolerance for seaweed chemical defenses (Steinberg 1992, Sotka \& Hay 2002). Ascophyllum nodosum contained higher constitutive levels of phlorotannins in grazer-free controls from North America (4 to $5 \%$ in apical tips and 7 to $8.5 \%$ in basal shoots) than European controls ( 3.5\% in apical tips, Pavia \& Toth $2000 ; \sim 2.9 \%$ in apical shoots, Toth \& Pavia $2000 ; \sim 3.2 \%$ in annual shoots, Borell et al. 2004; $\sim 3.3 \%$ in apical shoots and $\sim 4.0 \%$ in basal shoots, Toth et al. 2005). Surprisingly, these constitutive phlorotannin levels in controls from North America were also greater than induced levels of European seaweeds (3.4\% in apical shoots, Toth \& Pavia $2000 ; 3.7 \%$ in apical tips and $6.3 \%$ in basal shoots, Toth et al. 2005). Thus, high constitutive levels in North American populations may have selected for herbivores capable of tolerating these defenses.

An alternative hypothesis to explain the differences between this study and those of European populations is that our Ascophyllum nodosum populations were expressing inducible defenses during collection, thereby preventing the use of true controls. Support for this hypothesis is unlikely for the following 2 reasons. First, we collected seaweeds without severe grazing damage, similar to European studies that used undamaged seaweeds (defined as those 'without severe grazing marks'; Pavia \& Toth 2000). Thus, differences in grazing history between populations were not apparent. Second, inducible defenses in our controls would most likely have relaxed during our $26 \mathrm{~d}$ induction phase. In similar grazer-free conditions, inducible defenses in multiple seaweed species disappear within 12 to $14 \mathrm{~d}$ (Rohde et al. 2004, Molis et al. 2006).

Inducible defenses can strongly affect consumer feeding, performance, and population dynamics (Karban \& Baldwin 1997, Stout et al. 1998). Geographic variation in seaweed defenses may strongly influence consumer population dynamics because consumers encountering defended prey should be more negatively affected than consumers encountering either undefended prey or those with poorly developed defenses. Moreover, the modification of consumer-algae interaction coefficients by algal defenses may have important implications for the relative importance of herbivory to rocky shore community dynamics. For example, our results suggest that littorinid snails may have a more important influence on algal communities on North Amer- 
ican rather than European shores because North American algae do not display induced defenses. The frequency and importance of such complex interactions will be missed if we continue to focus on the defenses of single populations. By comparing the induced defenses of prey populations across broad spatial scales, we will improve our understanding of the ecology and evolution of inducible defenses and their influence on consumer-prey interactions.

Acknowledgements. This research was supported by the National Science Foundation (OCE-0240265) and the National Parks Ecological Research Fellowship Program, a partnership between the National Park Service, the Ecological Society of America, and the National Park Foundation funded through a generous grant from the Andrew W. Mellon Foundation. Critical laboratory assistance was provided by G. Bernachez, E. Blume, E. Bryson, F. Cent, T. Dwyer, T. Hajduk, N. Macrae, and E. Moore. J. McDonough maintained the seawater system. Comments by 3 anonymous reviewers improved the manuscript and are most appreciated.

\section{LITERATURE CITED}

Amsler CD, Fairhead VA (2006) Defensive and sensory chemical ecology of brown algae. Adv Bot Res 43:1-91

Bolser RC, Hay ME (1996) Are tropical plants better defended? Palatability and defenses of temperate versus tropical seaweeds. Ecology 77:2269-2286

Bolser RC, Hay ME (1998) A field test of inducible resistance to specialist and generalist herbivores using the water lily Nuphar luteum. Oecologia 116:143-153

Borell EM, Foggo A, Coleman RA (2004) Induced resistance in intertidal macroalgae modifies feeding behaviour of herbivorous snails. Oecologia 140:328-334

Bronmark C, Miner JG (1992) Predator induced phenotypical change in body morphology in Crucian carp. Science 258: $1348-1350$

Chapman ARO (1995) Functional ecology of fucoid algae: twenty-three years of progress. Phycologia 34:1-32

Cronin G, Hay ME (1996) Induction of seaweed chemical defenses by amphipod grazing. Ecology 77:2287-2301

Dudgeon SR, Kübler JE, Wright WA, Vadas RL, Petraitis PS (2001) Natural variability in zygote dispersal of Ascophyllum nodosum at small spatial scales. Funct Ecol 15:595-604

Harvell CD (1998) Genetic variation and polymorphism in the inducible spines of a marine bryozoan. Evolution 52:36-42

Karban R, Baldwin IT (1997) Induced responses to herbivory, University of Chicago Press, Chicago, IL

Kubanek J, Lester SE, Fenical W, Hay ME (2004) Ambiguous role of phlorotannins as chemical defenses in the brown alga Fucus vesiculosus. Mar Ecol Prog Ser 277:79-93

Lindquist N, Hay ME (1996) Palatability and chemical defense of marine invertebrate larvae. Ecol Monogr 66:431-450

Molis M, Korner J, Ko YW, Kim JH, Wahl M (2006) Inducible responses in the brown seaweed Ecklonia cava: the role of grazer identity and season. J Ecol 94:243-249

Parejko K, Dodson S (1991) The evolutionary ecology of an antipredator reaction norm: Daphnia pulex and Chaoborus americanus. Evolution 45:1665-1674

Pavia H, Toth GB (2000) Inducible chemical resistance to herbivory in the brown seaweed Ascophyllum nodosum. Ecology 81:3212-3225

Editorial responsibility: Kenneth Heck (Contributing Editor), Dauphin Island, Alabama, USA
Pennings SC, Silliman BR (2005) Linking biogeography and community ecology: latitudinal variation in plantherbivore interaction strength. Ecology 86:2310-2319

Reid DG, Rumbak E, Thomas RH (1996) DNA, morphology and fossils: phylogeny and evolutionary rates of the gastropod genus Littorina. Philos Trans R Soc Lond B 351: 877-895

Rohde S, Molus M, Wahl M (2004) Regulation of antiherbivore defence by Fucus vesiculosus in response to various cues. J Ecol 92:1011-1018

Sotka EE, Hay ME (2002) Geographic variation among herbivore populations in tolerance for a chemically rich seaweed. Ecology 83:2721-2735

Sotka EE, Taylor RB, Hay ME (2002) Tissue-specific induction of resistance to herbivores in a brown seaweed: the importance of direct grazing versus waterborne signals from grazed neighbors. J Exp Mar Biol Ecol 277:1-12

Stachowicz JJ, Hay ME (1999) Mutualism and coral persistence: the role of herbivor resistance to algal chemical defense. Ecology 80:2085-2101

Steinberg PD (1992) Geographical variation in the interaction between marine herbivores and brown algal secondary metabolites. In: Paul VJ (ed) Ecological roles of marine natural products. Comstock Publishing Associates, Ithaca, NY, p 51-92

Stout MJ, Workman KV, Bostock RM, Duffey SS (1998) Specificity of induced resistance in the tomato, Lycopersicon esculentum. Oecologia 113:74-81

Taylor RB, Sotka E, Hay ME (2002) Tissue-specific induction of herbivore resistance: seaweed response to amphipod grazing. Oecologia 132:68-76

Tollrian R, Harvell CD (1999) The ecology and evolution of inducible defenses, Princeton University Press, Princeton, NJ

Toth GB, Pavia H (2000) Waterborne cues induce chemical defense in a marine alga (Ascophyllum nodosum). PNAS 97:14418-14420

Toth GB, Langhamer O, Pavia H (2005) Inducible and constitutive defenses of valuable seaweed tissues: consequences for herbivore fitness. Ecology 86:612-618

Trussell GC (2000) Phenotypic clines, plasticity, and morphological trade-offs in an intertidal snail. Evolution 54: 151-166

Trussell GC, Nicklin MO (2002) Cue sensitivity, inducible defense, and trade-offs in a marine snail. Ecology 83: $1635-1647$

Trussell GC, Smith LD (2000) Induced defenses in response to an invading crab predator: an explanation of historical and geographic phenotypic change. PNAS 97:2123-2127

Trussell GC, Ewanchuk PJ, Bertness MD (2003) Traitmediated effects in rocky intertidal food chains: predator risk cues alter prey feeding rates. Ecology 84:629-640

Trussell GC, Ewanchuk PJ, Bertness MD, Silliman BR (2004) Trophic cascades in rocky shore tide pools: distinguishing lethal and nonlethal effects. Oecologia 139: 427-432

Van Alstyne KL (1995) Comparison of three methods for quantifying brown algal polyphenolic compounds. J Chem Ecol 21:45-58

Van Alstyne KL, Dethier MN, Duggins DO (2001) Spatial patterns in macroalgal chemical defenses. In: McClintock JB, Baker BJ (eds) Marine chemical ecology. CRC Press, Boca Raton, FL

Van Tienderen PH (1991) Evolution of generalists and specialists in spatially heterogeneous environments. Evolution 45:1317-1331

Submitted: April 10, 2006; Accepted: August 15, 2006

Proofs received from author(s): February 27, 2007 